Organizadora deste número

Colaboradores deste número

\section{JUSSARA ABRAÇADO}

Doutora em Linguística pela Universidade Federal do Rio de Janeiro e atua, na Universidade Federal Fluminense, como Professora Titular de Linguística, na graduação e Pós-Graduação. Coordenadora da Linha de Pesquisa Teorias e Análise Linguística do Programa de Pós-Graduação em Estudos de Linguagem da UFF. É líder do grupo de pesquisa Linguagem em uso, cognição e gramática, cadastrado no $\mathrm{CNPq}$, que reúne pesquisadores da UFF, da Universidade Católica Portuguesa e Universidade Aberta de Lisboa e membro do Grupo de Investigação Linguagem, cognição e sociedade, cadastrado na Fundação para Ciência e Tecnologia (FCT) de Portugal. Dedica-se a estudos na área de Linguística, com ênfase em Sociolinguística, Linguística Funcional e Sociolinguística Cognitiva.

\section{ABDELHAK RAZKY}

Possui graduação em Língua e Literatura Inglesa - Université Hassan II Casablanca (1986), mestrado em Lingüística - Université de Toulouse Le Mirail (1987), doutorado em Linguística - Université de Toulouse Le Mirail (1992) e pós-doutorado - Université de Toulouse Le Mirail (2003). Atualmente é professor associado nivel 4 da Universidade Federal do Pará e bolsista de produtividade em pesquisa do CNPq - Nível 2. Tem experiência na área de Linguística, com ênfase em Sociolinguística, geografia linguística, dialetoligia, socioterminologia e ensino aprendizagem de línguas, atuando principalmente nos seguintes temas: sociolinguística, geografia linguística, variação fonética e lexical, socioterminologia, tecnologias de informação e comunicação no ensino aprendizagem de línguas e tratamento automático e estatístico de dados linguísticos.

\section{AMANDA DINUCCI ALMEIDA BUHLER VELASCO}

Doutoranda em Estudos de Linguagem na Pontifícia Universidade Católica do Rio de Janeiro, com bolsa pelo Conselho Nacional de Desenvolvimento Científico e Tecnológico (CNPq). Mestre em Estudos de Linguagem pela Pontifícia Universidade Católica do Rio de Janeiro (2014), com bolsa pelo Conselho Nacional de Desenvolvimento Científico e Tecnológico (CNPq). Possui graduação em Letras (Português/Inglês) pela Universidade do Estado do Rio de Janeiro (2011). Tem experiência na área de Lingüística, com ênfase em Pragmática, Análise da Conversa e Sociolinguística Interacional.

\section{ANA CRISTINA OSTERMANN}

Professora Titular no Programa de Pós-Graduação em Linguística Aplicada da Universidade do Vale do Rio dos Sinos (UNISINOS) 
e Bolsista Produtividade do CNPq. É PhD em Linguística pela University of Michigan (EUA), Mestre em Inglês pela Universidade Federal de Santa Catarina (UFSC) e Licenciada em Letras (Português-Inglês) pela Universidade do Vale do Rio dos Sinos (UNISINOS). Em 2008-2009, realizou estágio de Pós-Doutorado na University of California, Los Angeles (UCLA), com projeto de interface entre Antropologia, Sociologia e Linguística Aplicada. É atual Coodenadora Adjunta do Comitê Assessor de Artes e Letras da FAPERGS. Em 2015, recebeu o Prêmio Pesquisadora Destaque da UNISINOS e em 2013, o Prêmio Pesquisadora Gaúcha na Área de Letras, Linguística e Artes, concedido pela FAPERGS. Foi presidenta eleita da International Gender and Language Association (IGALA), entre 2010 a 2012. Suas publicações nos últimos anos incluem artigos em periódicos internacionais (Pragmatics, Language \& Communication, Language in Society, Discourse \& Society, Gender \& Language Journal, and English for Specific Purposes Journal) e nacionais (Delta, Linguagem em (Dis)curso, Veredas, ALFA, Calidoscópio, Cadernos de Saúde Pública, Revista de Psicologia, Psicologia: Reflexão e Crítica, Veredas), entre outras.

\section{ANA PAULA ANTUNES ROCHA}

Graduada em Letras (1997), mestre em Letras (2001) pela UFJF e doutora em Letras (2006) pela PUC-RJ. Realizou estágio pósdoutoral em Letras Vernáculas na UFRJ (2012). Leciona Língua Portuguesa e Linguística no curso de Letras da UFOP. Como pesquisadora, interessa-se sobretudo pela descrição e pela análise do português escrito e falado em Minas Gerais, em perspectiva tanto sincrônica quanto diacrônica, especialmente no que tange às formas tratamentais, às formas pronominais e ao léxico.

\section{ANNA ELIZABETH BALOCCO}

Graduada em Letras Anglo-germânicas pela Universidade de São Paulo (1976), mestre em Letras pela Universidade Federal Fluminense (1985) e doutora em Linguística pela Universidade Federal do Rio de Janeiro (2000). Pós-doutora em Estudos da Linguagem pela UFF (2007), é Professora Associada do Departamento de Letras Anglogermânicas da Universidade do Estado do Rio de Janeiro e atua como docente no Programa de Pós-Graduação em Letras na mesma instituição. Tanto na graduação (Línguas Estrangeiras Modernas) quanto na pós-graduação (área de concentração em Linguística) tem atuado na área da Análise do Discurso, ocupando-se principalmente dos seguintes temas: sujeito e identidade, no âmbito dos discursos acadêmico e midiático. 


\section{BEATRIZ DARUJ GIL}

Mestre em Didática pela Faculdade de Educação da Universidade de São Paulo (1997) e Doutora em Linguística pela Faculdade de Filosofia, Letras e Ciências Humanas da Universidade de São Paulo (2002). Atualmente é professora doutora da Universidade de São Paulo, na área de Filologia e Língua Portuguesa, e coordena, desde 2007, a área de Português do Centro de Línguas da Faculdade de Filosofia, Letras e Ciências Humanas da USP. Tem experiência na área de Letras, com ênfase em Língua Portuguesa, atuando principalmente nas seguintes áreas: lexicologia, léxico e ensino e ensino de português para falantes de outras línguas.

\section{BRUNA FERNANDA CÂNDIDO}

Mestre em Língua Portuguesa pela Universidade Federal do Rio de Janeiro (2013) e graduada em Português / Francês pela Universidade Federal do Rio de Janeiro (2010). Tem experiência na área de Letras, com ênfase em Língua Portuguesa, atuando principalmente no seguinte tema: sufixos de grau.

\section{CAMILO ROSA SILVA}

Graduado em Letras pela Universidade Federal do Rio Grande do Norte (1989); Mestre em Letras pela Universidade Federal da Paraíba (1999); Doutor em Letras pela Universidade Federal da Paraíba (2005), com Doutorado Sanduíche na Universidade Federal de Santa Catarina. Atualmente é vinculado à Universidade Federal da Paraíba onde atua na Graduação em Letras e na Pós-Graduação em Linguística.

\section{CARLOS ALEXANDRE GONÇALVES}

Professor da Faculdade de Letras da UFRJ desde 1994, instituição em que se doutorou em 1997 e na qual atua, desde 1998, no Programa de Pós-graduação em Letras Vernáculas. Tem pós-doutoramento, subvencionado pelo $\mathrm{CNPq}$, em interface morfologia-fonologia (UNICAMP, 2001). É pesquisador da área de Linguística, com ênfase em morfologia e fonologia do português, atuando, principalmente, nos seguintes temas: fronteiras internas da morfologia, morfologia não-concatenativa, interface morfologia-fonologia e processos de formação de palavras. É autor dos livros "Iniciação aos estudos morfológicos: flexão e Derivação em português" (Ed. Contexto, 2011), "Introdução à Morfologia Não-linear" (Ed. Publit, 2009) e "Otimalidade em foco: morfologia e fonologia do português" (Ed. Publit, 2009) e de diversos capítulos de livros e artigos científicos publicados tanto no Brasil quanto no exterior. É coordenador do 
NEMP (Núcleo de Estudos Morfossemânticos do Português), ao lado de Maria Lúcia Leitão de Almeida.

\section{CAROLINA LINDENBERG LEMOS}

Doutora em Linguística pela Universidade de São Paulo e em Langues et Lettres pela Universidade de Liège (2015 - cotutela). Realizou estágio de mobilidade internacional na Universidade de Paris VIII, sob supervisão do Prof. Dr. Denis Bertrand (2013). Atualmente é presidente da Association de Jeunes Chercheurs en Sémiotique, membro do Grupo de Estudos Semióticos da USP e examinadora do IELTS, junto ao British Council. Tem experiência na área de Linguística, com ênfase em Semiótica, atuando principalmente nos seguintes temas: epistemologia da semiótica, historiografia linguística, estrutura linguística e enunciação.

\section{CRISTIANE DALL' CORTIVO LEBLER}

Graduada em Letras/Português pela Universidade Federal do Rio Grande (2006). É Mestre (2009) e Doutora (2013) em Linguística e Letras pela Pontifícia Universidade Católica do Rio Grande do Sul com dissertação e tese na linha de pesquisa Texto, Enunciação, Discurso: teoria e prática. Atualmente, atua como professora do Programa de Pós-Graduação em Letras - Mestrado em Leitura e Cognição da Universidade de Santa Cruz do Sul. Áreas de interesse: Semântica; Argumentação; Enunciação.

\section{CRISTIANE MARIA SCHNACK}

Licenciada em Língua Inglesa pela Universidade do Vale do Rio dos Sinos (2004) e graduação em Licenciatura Curta Em Ciências Físicas e Biológicas pelo Centro Universitário Univates (1998). Mestre em Linguística Aplicada pela Universidade do Vale do Rio dos Sinos (2006), doutora em Linguística Aplicada na mesma instituição. Atualmente é professora da universidade. Tem experiência na área de Linguística, com ênfase em Linguística Aplicada, e no ensino de Língua Inglesa como segunda língua. Dentre seus interesses estão: ensino e aprendizagem de idiomas, especialmente Língua Inglesa, formação de professores, socialização da linguagem, desenvolvimento infantil, e gênero social; e as tradições de pesquisa com as quais tem trabalhado são a sociolinguística interacional, a antropologia linguística, a etnografia, e a fala-em-interação social.

\section{DAIANE BALDASSO BOHM}

Mestranda no Programa de Pós-Graduação em Linguística Aplicada (PPGLA) na Universidade do Vale do Rio dos Sinos (UNISINOS). 
Graduada no curso de Letras: Habilitação Inglês (2015) e em Comércio Exterior (2007) na mesma universidade. Atuou como Bolsista de Iniciação Científica com bolsa FAPERGS (2015) e é membra do grupo de pesquisa Fala-em-interação (FEI), coordenado pela Profa. Dra. Ana Cristina Ostermann, do Programa de PósGraduação em Linguística Aplicada da UNISINOS.

\section{EDVALDO BALDUINO BISPO}

Licenciado em Letras, com habilitação em Línguas Portuguesa e Inglesa e respectivas Literaturas (1999), possui Mestrado (2003) e Doutorado (2009) em Estudos da Linguagem, na área de concentração em Linguística Aplicada, pela UFRN. Atualmente, é Professor Adjunto IV da Universidade Federal do Rio Grande do Norte, Câmpus de Natal, onde atua nas áreas de Língua Portuguesa, na graduação, e de Linguística, na pós-graduação. É Coordenador do Programa de Pós-graduação em Estudos da Linguagem (PPgEL/ UFRN), pesquisador do Grupo de Estudos Discurso \& Gramática, desenvolve pesquisas e orienta trabalhos contemplando os seguintes temas: ensino de língua portuguesa, funcionalismo, adjetivos, orações adjetivas, estratégias de relativização, transitividade, estrutura argumental e padrões construcionais morfossintáticos

\section{ELISA BATTISTI}

Licenciada em Letras Português Inglês pela UCS (1987), mestre em Letras pela UFRGS (1993) e doutora em Linguística e Letras pela PUCRS (1997). É Professora Adjunta do Instituto de Letras da UFRGS, Departamento de Linguística, Filologia e Teoria Literária. Atua nas Linhas 'Fonologia e Morfologia' e 'Sociolinguística' do Programa de Pós-Graduação em Letras, como orientadora de mestrado e doutorado, e nas disciplinas de Linguística na Graduação em Letras. É membro dos grupos de pesquisa Aspectos Fonológicos do Português Brasileiro-IV (PUCRS), Círculo Linguístico: Fonologia e Morfologia (UFRGS), Descrição Sócio-Histórica das Vogais do Português do Brasil (UFMG), Estudos de Teoria Fonológica (PUCRS). É pesquisadora do CNPq.

\section{ERNANI CESAR DE FREITAS}

Pós-doutor em Linguística Aplicada e Estudos da Linguagem - PUCSP/LAEL (2011); Doutor em Letras, área de concentração Lingüística Aplicada (PUCRS/2006); Mestre em Linguística Aplicada pela Universidade do Vale do Rio dos Sinos (UNISINOS/2002). Possui graduação em LETRAS - Português/Inglês e respectivas Literaturas, pelo Centro Universitario La Salle (1999). Experiência na área de 
Letras, com ênfase em Língua Portuguesa e Linguística Aplicada, nos temas relacionados à linguagem e trabalho, texto e discurso, leitura e formação do leitor; na área da Comunicação e cultura: comunicação socio-organizacional, cultura e identidade. Cursou MBA Gestão Empresarial na UFRGS e MBA Executivo na FGV-RJ. Professor (Titular) de Ensino Superior na Universidade Feevale, Programa de Pós-graduação em Processos e Manifestações Culturais, e professor permanente no PPG em Letras na Universidade de Passo Fundo (RS). Integrante de conselhos editorias e parecerista ad hoc de revistas acadêmicas.

\section{FÁBIO DA SILVA FORTES}

Graduado em Letras Clássicas pela Universidade Federal de Juiz de Fora (2005), Mestre (2008) e Doutor (2012) em Linguística (Estudos Clássicos) pela Universidade Estadual de Campinas e atualmente cursa Doutorado em Filosofia (Filosofia Antiga) pela Universidade Federal de Minas Gerais (2015-). É Professor Adjunto de Latim e Grego Clássico da Universidade Federal de Juiz de Fora. Tem experiência na área de Letras e Filosofia, com ênfase em Estudos Clássicos, atuando principalmente nos seguintes temas: gramática antiga, Platão e ensino de línguas clássicas.

\section{FELIPE MORAIS DE MELO}

Licenciado em Letras - Língua Portuguesa, Inglesa e Literaturas (2008) pela Universidade Potiguar (UnP) e em Letras - Língua Portuguesa (2009) pela Universidade Federal do Rio Grande do Norte (UFRN). Mestre pelo Programa de Pós-Graduação em Estudos da Linguagem (PPgEL) da UFRN na área de Linguística Aplicada (2012) e doutorando pelo mesmo Programa de Pós-Graduação e na referida área de pesquisa, com período sanduíche de 1 ano na Universidad Autónoma de Querétaro (México). Professor efetivo de Língua Portuguesa e Literatura do Instituto Federal de Educação, Ciência e Tecnologia do Rio Grande do Norte (IFRN). Minhas pesquisas têm se voltado especialmente para as questões da linguagem relacionadas à variação e à mudança.

\section{FRANCISCO EDUARDO ANDRADE}

Mestre em História pela Universidade Federal de Minas Gerais (1995) e doutor em História Econômica pela Universidade de São Paulo (2002). Tem pós-doutorado, com estágio na EHESS - Paris. Atualmente é coordenador da coleção Historiografia de Minas Gerais, da Autêntica Editora, e professor da Universidade Federal de Ouro Preto. Tem experiência na área de História, com ênfase em 
História do Brasil, atuando principalmente nos seguintes temas: metodologia da história, fronteira e territorialidade, história das práticas minerárias e agrárias, poderes e administração do Estado na América portuguesa.

\section{JOSEANE SOUZA}

Colaboradora em pós-doutorado no Programa de Pós-Graduação em Linguística Aplicada da UNISINOS (PNPD-Capes). Possui doutorado em Linguística Aplicada pela UNISINOS / CAPES (2015), com estágio sanduíche em Etnometodologia e Análise da Conversa (junho de 2013) sob supervisão do pesquisador Douglas W. Maynard na Universidade de Wisconsin-Madison (UW). Atualmente é editora assistente da Revista Calidoscópio (Qualis A2). Seus interesses de pesquisa incluem interações entre profissionais da saúde e pacientes sob a perspectiva da Análise da Conversa, interações em organizações públicas e privadas em contextos diversos e questões de gênero social e identidade no discurso. Quanto à docência, sua experiência compreende a produção textual em gêneros acadêmicos diversos, em língua portuguesa e inglesa, e as áreas afins à Análise da Conversa, à Sociolinguística Interacional e à Pragmática.

\section{LARISSA COSTA DA MATA}

Graduada em Letras - Língua Inglesa e Literaturas pela Universidade Federal de Santa Catarina (2006) e mestrado em Literatura Brasileira pelo Programa de Pós-Graduação em Literatura da Universidade Federal de Santa Catarina (2008). É doutora em Teoria da Literatura pela Universidade Federal de Santa Catarina com a tese "Genealogia e primitivismo no modernismo brasileiro: o mundo perdido de Flávio de Carvalho", sob a orientação do Prof. Dr. Raúl Antelo (defendida em 2013). Foi professora visitante de português para estrangeiros na Universidade de Leiden, Holanda, e pesquisadora visitante em Yale, nos Estados Unidos. De 2013 a 2014, atuou como Leitora de Português e Cultura Brasileira na Universidade de Pequim, na China, lecionando cursos de História e Cultura do Brasil, Literatura Brasileira, Língua Portuguesa e organizando eventos junto ao Núcleo de Cultura Brasileira da Universidade de Pequim e à Embaixada do Brasil.

\section{LETÍCIA CORRÊA}

Obteve PhD., com tese em Psicolinguística, na University of London (LSE), em 1986. Desde então é professora da PUC-Rio, atuando no Programa de Pós-Graduação em Letras / Estudos da Linguagem, o qual coordenou de dezembro de 2011 a dezembro de 2015. 
Fundou e coordena do LAPAL (Laboratório de Psicolinguística e Aquisição da Linguagem), coordenou o GT (Grupo de Trabalho) de Psicolinguística da ANPOLL (Associação Nacional de PósGraduação em Letras e Linguística), de 1988-2002 e foi, por duas vezes $(2003$; 2005), pesquisador-visitante no então Laboratoire de Psychologie Expérimentale (Université Paris 5). Atuou como coordenadora da área de Letras e Artes da FAPERJ, de 1995 a 1999, e como membro titular do Comitê Assessor de Letras e Linguística do CNPq, de 2012 a 2015. Como coordenadora do GPPAL (Grupo de Pesquisa em Processamento e Aquisição da Linguagem), desenvolve um programa de pesquisa que integra teorias psicolinguística e linguística (na vertente minimalista).

\section{LUCIANA ANDRADE PAULA}

Graduanda da Faculdade de Letras da Universidade Federal de Juiz de Fora.

\section{LUCIANA MARINO NASCIMENTO}

Docente de Teoria Literaria do Departamento de Ciência da Literatura da Faculdade de Letras da Universidade Federal do Rio de Janeiro. Docente do Programa Interdisciplinar de Pós-Graduacão em Linguística Aplicada. Universidade Federal do Rio de Janeiro. Bolsista de Produtividade em Pesquisa (PQ2) do CNPq- Conselho Nacional do Desenvolvimento Científico e Tecnológico.Doutora em Teoria e História Literária pela UNICAMP.

\section{LUIS HENRIQUE BOAVENTURA}

Doutorando em Letras (UPF). Mestrado em Letras pela Universidade de Passo Fundo (UPF-2013). Possui graduação em Comunicação Social - Habilitação em Jornalismo pela Universidade de Passo Fundo (UPF-2009). Tem experiência na área de Linguística, com ênfase em Análise do Discurso. Escreve para a revista eletrônica de cinema Multiplot (http://multiplotcinema.com.br) e para o site de cinema Cineplayers (http://www.cineplayers.com/), da Globo.com.

\section{LUIZ FERNANDO MATOS ROCHA}

Doutor em Linguística (UFRJ, 2004), mestre em Linguística (UFJF, 2000), graduado em Letras (Português e Latim, UFJF, 1998) e bacharel em Comunicação Social (Jornalismo, UFJF, 1991). É docente e pesquisador da Faculdade de Letras da Universidade Federal de Juiz de Fora (FALE/UFJF) e tem experiência na área de Linguística, com ênfase em Linguística Cognitiva, atuando principalmente nos seguintes temas: cognição, discurso reportado, fictividade e 
gramática. Cumpriu estágio pós-doutoral (bolsista da CAPES Processo: BEX 4084/10-1), na Universidade Católica Portuguesa (Braga), no âmbito do Centro de Estudos Filosóficos e Humanísticos (CEFH), no qual atua como membro integrado do projeto de investigação "Sociolinguística Cognitiva e Variação do Português Europeu e Brasileiro", pertencente ao grupo de investigação "Estudos de Linguagem e Comunicação".

\section{MARCELA ZAMBOLIM DE MOURA}

Graduada em Letras - Português/Inglês - (2003-2006) e mestre em Linguística (2007-2009) pela Universidade Federal de Juiz de Fora. É doutoranda em Linguística pela Universidade Federal de Juiz de Fora (início 2013) e professora efetiva do Instituto Federal de Educação, Ciência e Tecnologia do Sudeste de Minas Gerais - IFET, campus Rio Pomba. Tem experiência em Linguística, com os temas Cláusulas Encaixadas Subjetivas, Modalização, Avaliação, Construcionalização gramatical, Abordagem construcional da mudança.

\section{MARCELO AMORIM SIBALDO}

Graduado em Letras pela Universidade Federal de Alagoas (2004) e doutor em Linguística pela Universidade Federal de Alagoas (2009), com realização de período sanduíche no Graduate Center da City University of New York, na cidade de Nova Iorque, Estados Unidos. Atualmente é professor adjunto III da Universidade Federal Rural de Pernambuco e professor colaborador do Programa de PósGraduação em Letras da Universidade Federal de Pernambuco. Tem experiência na área de Linguística, atuando principalmente na área da Teoria da Gramática, estudando aspectos diacrônicos e sincrônicos da sintaxe das línguas naturais, mais especificamente do português brasileiro. É líder do Grupo de Estudos em Teoria da Gramática (GETEGRA) da UFRPE e atua como pesquisador do Programa de Estudos Linguísticos (PRELIN) da UFAL, ambos cadastrados no Diretório dos Grupos de Pesquisas do CNPq.

\section{MÁRCIA DO PRADO ANDRADE}

Graduanda da Faculdade de Letras da Universidade Federal de Juiz de Fora.

\section{MARCUS MAIA}

Doutor em linguística pela University of Southern California - USC, (1994). Realizou estágio de pós-doutorado na área de Processamento da Linguagem como pesquisador visitante na City University of New York - CUNY (2003-2004). Atualmente é Professor Titular de 
Linguística do Departamento de Linguística e do Programa de Pósgraduação em Linguística da Faculdade de Letras da Universidade Federal do Rio de Janeiro. É bolsista de Produtividade em Pesquisa, nível 1C (CNPq) e Cientista do Nosso Estado (FAPERJ) no triênio 2015-2018. Foi professor visitante no Departamento de Línguas, Literaturas e Culturas e no Language Acquisition Research Center (LARC), da University of Massachusetts, Amherst, em 2012 e no Departamento de Linguística da Massey University, Nova Zelândia, em 2015. Fundou e coordena o Laboratório de Psicolinguística Experimental (LAPEX), grupo de pesquisa da UFRJ, registrado no CNPq, em 2001. Coordenou o Grupo de Trabalho de Psicolinguística da ANPOLL no biênio 2006-2008.

\section{MARIA ANGÉLICA FURTADO DA CUNHA}

Professora titular de Linguística da Universidade Federal do Rio Grande do Norte. Possui doutorado em Linguística pela Universidade Federal do Rio de Janeiro (1989), mestrado em Linguística pela Universidade de Brasília (1978) e bacharelado e licenciatura em Letras pela Universidade Federal do Rio de Janeiro (1975/6). Fez dois estágios de pós-doutorado na University of California, Santa Barbara, e um na Universidade Federal Fluminense. Tem experiência na área de Linguística, com ênfase em Linguística Funcional, atuando principalmente nos seguintes temas: gramaticalização, transitividade, gramática de construções, estrutura argumental e ensino de gramática.

\section{MARIA DO CARMO LEITE OLIVEIRA}

Licenciada em Português e Literaturas de Língua Portuguesa pela Universidade Federal do Rio de Janeiro (1970), mestre em Língua Portuguesa pela Pontifícia Universidade Católica do Rio de Janeiro (1973), doutora em Linguística Aplicada ao Português pela Pontifícia Universidade Católica do Rio de Janeiro (1992) e pós-doutorado pela Universidade de Lisboa (2005). Atualmente é Professora Adjunta da Pontifícia Universidade Católica do Rio de Janeiro, orientando dissertações e teses e atuando como professora convidada em disciplinas de pós-graduação stricto sensu no Departamento de Letras e lato sensu no Instituto de Administração e Gerência IAG da PUC-Rio. Atua na área de Linguística Aplicada e Análise do Discurso, sendo seus interesses de pesquisa a interação em contextos institucionais: a linguagem e as práticas profissionais, nos cenários empresarial, educacional, jurídico, político e da mídia; a comunicação nas organizações pós-burocráticas, face, identidade e (in)polidez em interações face a face e mediada pela tecnologia; 
o trabalho no mundo globalizado e as práticas de atendimento; competência interpessoal e (in)sucesso profissional.

\section{MARIA HOZANETE ALVES DE LIMA}

Doutora em Letras e Lingüística pela Universidade Federal de Alagoas (2003). Realizou pós-doutorado no Institut de Textes et Manuscrits Modernes (ITEM-ENS-CNRS/Paris-França) - 2014. Atualmente, é professora do Departamento de Letras e do Programa de Pós-Graduação em Estudos da Linguagem da Universidade Federal do Rio Grande do Norte.

\section{MARIA LUCIA LEITÃO DE ALMEIDA}

Professora Associada do Departamento de Letras Vernáculas da Faculdade de Letras da Universidade Federal do Rio de Janeiro (UFRJ). Líder, ao lado de Carlos Alexandre Victorio Gonçalves, do grupo de pesquisa Núcleo de Estudos Morfossemânticos do Português (NEMP). Membro do grupo de pesquisa Investigações (In)Formais em Língua(gem) e Cognição (InFoLinC), da UNIFESP. Doutora em Linguística pela Universidade Federal do Rio de Janeiro (1992). Assessora do Projeto Caipira (USP) Áreas de interesse: Linguística Cognitiva, Semântica, Morfologia, Léxico. Pós-doutorado em Semântica sob a supervisão de Rodolfo Ilari com subvencionamento do CNPq na UNICAMP (2004/2005). Pósdoutorado em Linguística Cognitiva sob a supervisão de Lilian Ferrari (UFRJ/2014-2015). É autora do livro "Linguística Cognitiva em foco: morfologia e Semântica" (Ed. Publit, 2009) e de diversos capítulos de livros e artigos científicos publicados tanto no Brasil quanto no exterior.

\section{MARTA ANAÍSA BEZERRA RAMOS}

Licenciada em Letras pela Universidade Federal da Paraíba (1992), com especialização em Especialização Em Língua Portuguesa pela Universidade Federal da Paraíba (1995), mestrado em Letras pela Universidade Federal da Paraíba (1998) e doutorado em Linguística pela Universidade Federal da Paraíba (2015). Atualmente é professor titular da Universidade Estadual da Paraíba. Tem experiência na área de Linguística, com ênfase em Teoria e Análise Linguística. Atuando principalmente nos seguintes temas: Referência demonstrativa, Memória discursiva, Anáfora, Dêixis.

\section{PAULA TATIANNE CARRÈRA SZUNDY}

Graduada em Letras - Faculdades Integradas Teresa D'ávilla (1995), mestre em Linguística Aplicada e Ensino de Línguas pela 
Pontifícia Universidade Católica de São Paulo (2001) e doutora em Linguística Aplicada e Estudos da Linguagem pela Pontifícia Universidade Católica de São Paulo (2005). Atualmente é professora adjunta do Departamento de Letras Anglo-Germânicas, professora permanente do Programa de Pós-Graduação Interdisciplinar em Linguística Aplicada da Universidade Federal do Rio de Janeiro e presidente da Associação de Linguística Aplicada do Brasil (biênio 2016-2017). Também foi presidente da ALAB no biênio 2010-2011. Tem experiência na área de Linguística Aplicada, com ênfase em formação de professores e seus interesses de pesquisa incluem: ensino-aprendizagem de línguas adicionais, formação de professores, gêneros discursivos e ensino, práticas de letramentos no ensino básico e/ou superior.

\section{RENÊ FORSTER}

Graduado em Letras pela Universidade do Estado do Rio de Janeiro (2005), mestre em Letras pela Universidade do Estado do Rio de Janeiro (2008) e doutor em Estudos da Linguagem pela Pontifícia Universidade Católica do Rio de Janeiro (2013).

\section{ROMÁRIO DUARTE SANCHES}

Doutorando em Linguística pela Universidade Federal do Pará (UFPA). Mestrado em Linguística pela Universidade Federal do Pará (UFPA). Especialização em Estudos Linguísticos e Análise Literária pela Universidade do Estado do Pará (UEPA). Graduação em Licenciatura Plena em Letras/Inglês pelo Instituto de Ensino Superior do Amapá (IESAP). Graduação em Bacharelado e Licenciatura em Ciências Sociais pela Universidade Federal do Amapá (UNIFAP). Integrante dos projetos de pesquisa: Atlas Linguístico do Brasil (ALiB), Geossociolinguística e Socioterminologia (GeoLinTerm) e Atlas Linguístico do Amapá (ALAP).

\section{SHEYLA PATRÍCIA TRINDADE DA SILVA COSTA}

Professora efetiva do Instituto Federal de Educação, Ciência e Tecnologia do Rio Grande do Norte - IFRN, na disciplina de Língua Portuguesa. Possui mestrado em Linguística pela Universidade Federal do Rio Grande do Norte (2003) e licenciatura em Letras pela mesma Universidade (1998). Tem experiência no ensino de Língua Portuguesa nos níveis fundamental, médio e superior. Atualmente é aluna do Doutorado em Linguística do Programa de Pós-Graduação em Estudos da Linguagem, da Universidade Federal do Rio Grande do Norte. 


\section{SOLANGE COELHO VEREZA}

Professora Titular da UniversidadeFederal Fluminense, com mestrado em Língua e Literatura pela Universidade de Londres, doutorado em Linguística Aplicada pela PUC-SP e Pós-Doutorado em Linguística pela USP. Orienta e publica, principalmente, na área da Linguística Cognitiva, com foco na metáfora.

\section{VIVIANE TEBALDI MORAS}

Graduanda em Letras - Licenciatura (Português e Literaturas) na Universidade Federal do Rio Grande do Sul. É bolsista de Iniciação Científica PIBIC/CNPq no plano de trabalho intitulado "O contraste capital-interior: padrões de variação linguística", vinculado à área de Linguística, com ênfase em Fonologia e Sociolinguística Variacionista. 